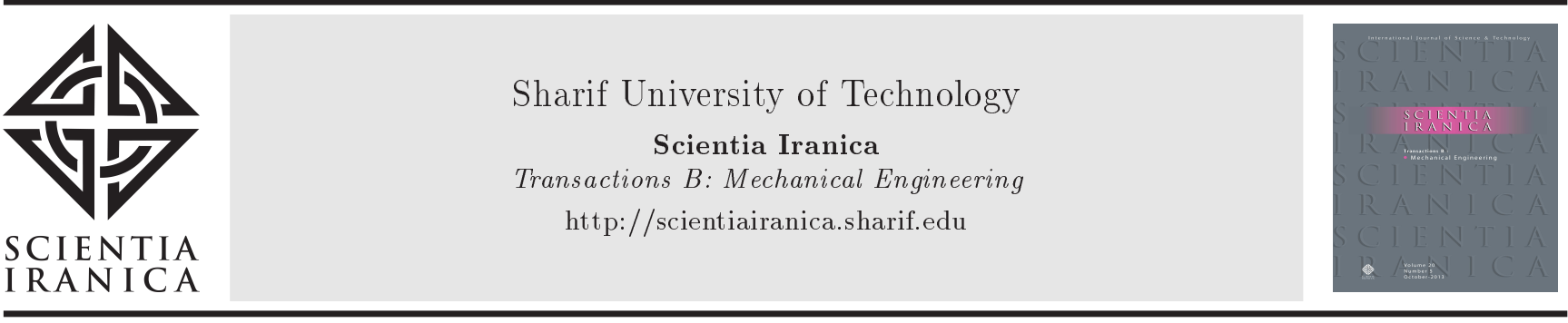

\title{
Numerical modeling of sand particle erosion at return bends in gas-particle two-phase flow
}

\author{
A. Farokhipour ${ }^{a}$, Z. Mansoori ${ }^{b, *}$, M. Saffar-Avval ${ }^{a}$, and G. Ahmadi ${ }^{c}$ \\ a. Department of Mechanical Engineering, Amirkabir University of Technology, Tehran, P.O. Box 15875- 4413, Iran. \\ b. Energy Research Center, Amirkabir University of Technology, Tehran, P.O. Box 15875- 4413, Iran. \\ c. Department of Mechanical and Aeronautical Engineering, Clarkson University, Potsdam, NY, USA.
}

Received 15 April 2018; received in revised form 28 July 2018; accepted 27 August 2018

\section{KEYWORDS}

Eulerian-Lagrangian approach;

Particle tracking;

Gas-solid erosion;

CFD-based erosion

modeling;

Return bends.

\begin{abstract}
In gas and oil industry, erosion damage to pipelines' bends and elbows due to the presence of sand particles has been a challenging issue. In this study, a computational model approach was used to evaluate the erosion rates at different vertical return bends: sharp bend, standard elbow, $180^{\circ}$ pipe bend, and long elbow. The airflow in the pipe was simulated using the SIMPLE method and the $k-\omega$ SST turbulence model. An EulerianLagrangian approach was used to predict particle trajectories and related erosion rates. Different particle sizes and mass flow rates were considered, and Oka model was used in these simulations to evaluate the erosion rate. Under the same condition, the simulation results indicated that the sharp return bends experienced the highest erosion rates, and the $180^{\circ}$ bends experienced the lowest erosion among the studied configurations. It was also found that the erosion rate was linearly proportional to the mass flow rate of particles for all cases studied.
\end{abstract}

(C) 2018 Sharif University of Technology. All rights reserved.

\section{Introduction}

Pipes are the major component of petroleum transportation systems. Erosion, caused by sand particles inside the piping systems, is a major concern in gas and oil industry. Although all pipes, whether inside or outside of wells, are subjected to erosion, the risk of erosion is higher where there is a greater deviation from the main pathway. Erosion is a surface damage caused by particle impingement on the walls. In petroleum transportation systems, the velocity and acceleration of particles, as well as the centrifugal effects of the pipe curvature, increase the chance of

\footnotetext{
*. Corresponding author. Tel./Fax: +982164542611

E-mail addresses: farokhipour_ali@aut.ac.ir ( $A$.

Farokhipour); z.mansoori@aut.ac.ir (Z.Mansoori);

mavval@aut.ac.ir (M. Saffar-Avval); gahmadi@clarkson.edu (G. Ahmadi)
}

doi: $10.24200 /$ sci. 2018.50801 .1871 solid particle impingement on the pipeline internal surface, thereby increasing the risk of erosion. In addition, the secondary flow, usually formed in the curvature downstream, changes the movement of the particles and results in a greater particle impingement on the walls [1]. Figure 1 shows erosion damage to the inner wall of a standard elbow along the outer radius [2].

The profound knowledge of erosion rate in the pipes and piping equipment contributes to creating an appropriate layout design to protect pipes from erosion and reduce subsequent damages and costs. The solid particle erosion depends on different factors: pipe geometry, pipe and particle materials, particle shape and size, and particle-laden fluid properties [3]. At the return bends, during the piping design, the pipe geometry and configuration of pipe joints are major parameters to be analyzed. This is the reason why erosion rate varies based on the movement of solid particles throughout the pipes with different geometries. 


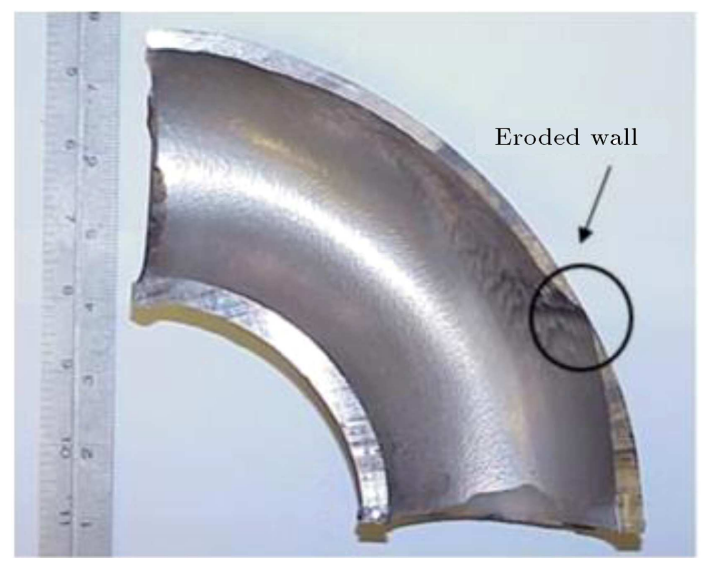

Figure 1. Erosion damage in a standard elbow [2].

Erosion has been a serious industrial issue in oil and gas industries, and numerous studies addressed erosion in elbows and other pipe fitting, as reported in the literature. For the first time, Finnie [4] investigated sand particle erosion in steel plates. Bitter [5] modified the Finnie's model. Sheldon and Finnie [6] examined the difference between the effects of brittle and ductile materials on erosion. Between 1972 and 1982, API standard [7] $\left(V_{e}=\frac{C}{\sqrt{\rho_{m}}}\right)$ and some other standards from other companies were developed. Based on API, Salama and Vankatesh [8] proposed the C-factor of 80100 for a gas flow and a C-factor of 300 for a liquid-gas flow. Russell et al. [9] proposed an equation to modify C-factor in API formula. In a study on the erosion rate of sand particles in a 6 -inche elbow containing methane, Shirazi [10] showed that pressure less than 70 bars did not affect the erosion rate. Chen et al. [11] studied erosion in a 2-inche elbow and plugged tee for two carrier flows of water and air. They showed that the Grant and Tabakoff stochastic rebound model [12] produced more realistic results, and the use of plugged tee instead of elbow did not necessarily lead to a reduction in erosion rate. Oka et al. [13] showed that particle velocity and impact angle, as well as hardness of material, were among the key parameters to predict erosion rate. Abdulla et al. [14] used the commercial code STAR-CCM+ and studied the effect of different flow velocities on erosion damage in an elbow in gas and oil pipelines using two erosion models. Mazumder [15] investigated the effect of gas and liquid velocity on the magnitude and location of maximum erosion in U-bend. In another study [16], Mazumder numerically and experimentally analyzed the erosion rate in S-bend with three different air velocities and six different particle sizes. Pereira et al. [17] modeled erosion for a two-phase gas-particle flow in a $90^{\circ}$ elbow. They applied models of Ahlert [18], Neilson and Gilchrist [19], Zhang et al. [20], and Oka et al. [21], and showed that the Oka model and stochastic rebound model were more realistic than the other models were.
Fan et al. [22] used Large Eddy Simulation (LES) to study the erosion rate by particle impact at a duct bend and three ribbed bends with different shapes. Their results demonstrated that the erosion rate could be significantly reduced by adding ribs, and the isosceles right-angled triangle ribs had the best anti-erosion performance among the studied configurations. Chen et al. [23] used CFD methods to investigate the erosive effects of a solid particle-laden airflow on the 45-, $60-$, and 90-degree elbow fittings of diameter of 40 $\mathrm{mm}$. They showed that the maximum erosion rate occurred near the output in all the three elbows; in addition, the erosion rate intensified with increasing the elbow angle. Mansouri et al. [24] predicted the erosion rate at a sharp $90^{\circ}$ bend containing a twophase water-sand flow, using the Eulerian-Lagrangian approach. They showed that tracing large particles with the standard wall-function and low-Re number produced logical solutions; however, tracing small particles with the standard wall-function produced nonphysical results. Viera et al. [25] used PIV technique to measure the slip velocity between air and solid particles in a direct impact geometry and, then, developed an erosion model. Zahedi et al. [26] used CFD methods to perform a parametric investigation into the erosion rate in a $90^{\circ}$ elbow with 3 inches of diameter and a high curvature ratio. They concluded that the maximum erosion occurred around the $45^{\circ}$ curvature. In addition, they observed a reduction in the erosion rate with increasing the pipe diameter. Duarte et al. [27] studied the erosion rate based on the four-way coupling of airparticle in the standard elbow and the bend equipped with a vortex chamber. They compared erosion rates in different particle mass loadings for both geometries. Their major finding was that the vortex chamber under high mass loading increased the cushioning effect and reduced the maximum erosion rate by $93 \%$ as compared to the elbow. Zheng et al. [28] performed a structure optimization of ball seat and assessed the erosion rate on the ball seat wall with different cone angles. They concluded that the cone angle from $20^{\circ}$ to $30^{\circ}$ is the proper range for ball seat, resulting in a lower erosion rate. In addition, the ball seat with a double-cone structure showed better erosion resistance. Predicting solid particle erosion in multiphase flow is a complex task due to existence of different flow patterns, and it is important to study the main parameters of multiphase flow. Zehtabiyan-Rezaie et al. [29] studied some of the most important characteristics of the stratified air-water flow in horizontal mini-channel by using a rule-based fuzzy inference system. Their results demonstrated that the system was an effective tool to avoid the considerable computational costs of the numerical methods. Banakermani et al. [30] performed a comprehensive numerical study on erosion damage due to particles, called black powder, for a 
range of elbow angles. In their research, two different flow orientations, horizontal-to-horizontal $(\mathrm{H}-\mathrm{H})$ and vertical-to-horizontal ( $\mathrm{V}-\mathrm{H})$ flows, were simulated. The most important findings were that the erosion rate in the $\mathrm{H}-\mathrm{H}$ case configuration was larger than that in $\mathrm{V}$ $\mathrm{H}$ case. Moreover, the location of maximum erosion on elbow's wall is about $55^{\circ}$ for the $\mathrm{V}-\mathrm{H}$ configurations and about $50^{\circ}$ for the $\mathrm{H}-\mathrm{H}$ ones.

Despite the conduction of many numerical and experimental studies on erosion, there are few comparative studies on the erosion rate at return bends. The aim of the current study is to evaluate the erosion rate caused by a solid particle-laden airflow at four different return bends, namely the sharp bend, standard elbow, $180^{\circ}$ pipe bend, and long elbow. To this end and to find the best configuration with higher erosion resistance, the fluid flow is first simulated in these geometries at the velocity of $20 \mathrm{~m} / \mathrm{s}$. Then, 150 and $300 \mu \mathrm{m}$ particles are released in the pipe at different mass flow rates and tracked. Afterwards, the magnitude and location of maximum erosion rate in these geometries are compared.

\section{Numerical modeling}

Numerical modeling of erosion consists of three main parts: First, the flow field is simulated. Second, discrete particles are released in the flow field at an appropriate concentration and are tracked, and their wall collisions are monitored. Third, the data of wallparticle collisions, including the velocity and angle at collision, are used; the erosion rate as a function of space and time is evaluated.

One of the most important issues in the multiphase flow simulation is the interaction between phases, which may present one-way, two-way, or four-way forms. The particle mass loading ratio is a parameter used for determining the coupling between phases and is defined as the ratio of mass flow rates of particle and continuous phases. Due to the low mass loading rate, the one-way coupling is used in the current study $\left(\varphi_{\max }=0.002\right)$.

\subsection{Flow modeling}

The governing equations for simulating incompressible and Newtonian fluid flow, including continuity and momentum equations, are given by:

$$
\begin{aligned}
\frac{\partial u_{i}}{\partial x_{i}}=0, & \\
\frac{\partial}{\partial x_{j}}\left(\rho u_{i} u_{j}\right)= & -\frac{\partial p}{\partial x_{i}}+\frac{\partial}{\partial x_{j}}\left[\mu\left(\frac{\partial u_{i}}{\partial x_{j}}+\frac{\partial u_{j}}{\partial x_{i}}\right)\right. \\
& \left.-\frac{2}{3} \mu \delta_{i j} \frac{\partial u_{l}}{\partial x_{l}}\right]+\frac{\partial}{\partial x_{j}}\left(-\rho \overline{u_{i}^{\prime}{ }_{i}^{\prime}{ }_{j}}\right),
\end{aligned}
$$

where $\rho$ is fluid density, $p$ is fluid pressure, $u$ is fluid velocity component, $\mu$ is dynamic viscosity of fluid, and $\delta_{i j}$ is unit tensor. To close the system of equations, the boussinesq hypothesis is used to model the Reynolds stresses by presenting an eddy viscosity:

$$
-\rho \overline{u_{i}^{\prime} u_{j}^{\prime}}=\mu_{t}\left(\frac{\partial u_{i}}{\partial x_{j}}+\frac{\partial u_{j}}{\partial x_{i}}\right)-\frac{2}{3} \delta_{i j}\left(\rho k+\mu_{t} \frac{\partial u_{k}}{\partial x_{k}}\right)
$$

To calculate the turbulent viscosity, $\mu_{t}$, the $k-\omega$ SST model is used to include the effects of turbulence, where this model is formulated as follows [31]:

$$
\begin{aligned}
& \frac{\partial(\rho k)}{\partial t}+\frac{\partial\left(\rho k u_{i}\right)}{\partial x_{i}}=\frac{\partial}{\partial x_{j}}\left[\Gamma_{k} \frac{\partial k}{\partial x_{j}}\right]+G_{k}-Y_{k} \\
& \frac{\partial(\rho \omega)}{\partial t}+\frac{\partial\left(\rho \omega u_{i}\right)}{\partial x_{i}}=\frac{\partial}{\partial x_{j}}\left[\Gamma_{\omega} \frac{\partial \omega}{\partial x_{j}}\right]+G_{\omega}-Y_{\omega}+D_{\omega}
\end{aligned}
$$

In these equations, $G_{k}$ and $G_{\omega}$ represent the generations of turbulent kinetic energy and $\omega$, respectively, $\Gamma_{k}$, and $\Gamma_{\omega}$ are the effective diffusivities of $k$ and $\omega, Y_{k}$ and $Y_{\omega}$ are the dissipation states of $k$ and $\omega$, and $D_{\omega}$ is the cross-diffusion term. These functions and other model constants can be found in [31].

The SIMPLE algorithm is used to couple velocity with pressure fields. Upwind second-order method is applied to discretize advective terms of the equations, while central difference method is used for diffusion terms.

\subsection{Particles tracking}

Momentum conservation equation for each particle, also known as particle movement equation, is as follows:

$$
\frac{d u_{i}^{p}}{d t}=\sum F=F_{D}+F_{g}+F_{L}+F_{P}+F_{V M}
$$

where $u_{i}^{p}$ is particle velocity in direction $i, F_{D}$ is drag force, $F_{g}$ represents the resultant of gravity and buoyancy forces acting on particle mass unit, $F_{L}$ is lift force, $F_{p}$ is pressure gradient force, and $F_{V M}$ is virtual mass force. The effect of pressure gradient and virtual mass forces in the particle equation of motion is neglected when the density of the fluid is much lower than that of the particles. Furthermore, the drag force plays a major role in the force acting on the particles by the fluid; therefore, in this work, the particle motion is mainly affected by drag force and gravity [32]. These forces are given as follows [33]:

$$
\begin{aligned}
& F_{D}=\left(\frac{18 \nu}{S d^{2}}\right) \frac{C_{D} \operatorname{Re}_{p}}{24}\left(u_{i}-u_{i}^{p}\right), \\
& F_{g}=\left(1-\frac{1}{S}\right) g_{i},
\end{aligned}
$$




$$
\begin{aligned}
& F_{L}=\frac{2 K \nu^{0.5} d_{i j}}{S d\left(d_{l k} d_{k l}\right)^{0.25}}\left(u_{i}-u_{i}^{p}\right), \\
& F_{p}=\left(\frac{1}{S}\right) u_{i}^{p} \frac{\partial u_{i}}{\partial x_{i}}, \\
& F_{V M}=\left(\frac{1}{2 S}\right) \frac{d}{d t}\left(u_{i}-u_{i}^{p}\right) .
\end{aligned}
$$

In these expressions, $S$ is the ratio of solid particles' density to carrier fluid flow density, $d$ is the diameter of particles, $g$ is the gravitational acceleration, $C_{D}$ is the drag coefficient, $K=2.594$ is a constant of Saffman lift force, $\nu$ is the kinematic viscosity of carrier fluid flow, $d_{i j}=\frac{1}{2}\left(\frac{\partial u_{i}}{\partial x_{j}}-\frac{\partial u_{j}}{\partial x_{i}}\right)$ is the deformation rate tensor, and $\operatorname{Re}_{p}=\frac{d\left|u_{i}-u_{i}^{p}\right|}{\nu}$ represents the particle Reynolds number. Haider and Levenspiel [34] suggested a model for the drag coefficient. In other words:

$$
\begin{aligned}
& C_{D}=\frac{24}{\operatorname{Re}_{p}}\left(1+b_{1} \operatorname{Re}_{p}^{b_{2}}\right)+\frac{b_{3} \operatorname{Re}_{p}}{b_{4}+\operatorname{Re}_{p}}, \\
& b_{1}=\exp \left(2.3288-6.4581 \Phi+2.4486 \Phi^{2}\right), \\
& b_{2}=0.0964+0.5565 \Phi, \\
& b_{3}=\exp \left(4.905-13.8944 \Phi+18.4222 \Phi^{2}-10.2599 \Phi^{3}\right), \\
& b_{4}=\exp \left(1.4681+12.2584 \Phi-20.7322 \Phi^{2}+15.8855 \Phi^{3}\right) .
\end{aligned}
$$

Herein, $\Phi$ is the particle shape factor, and $\Phi$ is equal to 1 for spherical particles. The Discrete Random Walk (DRW) model is used to model the effect of turbulence fluctuating velocities on the particle movement. In this model, a particle is trapped by an eddy in its lifetime, i.e., $\tau_{e}=2 \tau_{l}$, where $\tau_{l}$ is the particle Lagrangian integral time scale. The eddy-particle interaction continues until the eddy lifetime expires or the particle crosses the eddy boundaries. The particle eddy crossing time, $\tau_{\text {cross }}$, is obtained as follows:

$$
\tau_{\text {cross }}=-\tau L n\left(1-\frac{L_{e}}{\tau\left|u-u_{p}\right|}\right) .
$$

Herein, $\tau$ represents particle relaxation time, and $L_{e}$ represents the eddy length scale. During the eddy lifetime, the instantaneous fluid velocity sensed by the particle is as follows:

$$
\begin{aligned}
& u^{\prime}=\lambda_{i} u_{r m s}, \\
& \nu^{\prime}=\lambda_{j} \nu_{r m s}, \\
& w^{\prime}=\lambda_{k} w_{r m s},
\end{aligned}
$$

where $\lambda_{i}, \lambda_{j}, \lambda_{k}$ are the zero-mean Gaussian random numbers with the standard deviation of 1 , and $u_{r m s}$, $\nu_{r m s}, w_{r m s}$ are the RMS fluctuating components.

During particles' movements through the piping system, they may affect the pipe wall and rebound several times. To model particle-wall collisions, the stochastic rebound model proposed by Grant and Tabakoff [12] is used. They treated rebound dynamics of particles in a statistical sense based on experimental data for Aluminum 2024. The mean values of normal restitution coefficient, $e_{N o r}$, and tangential one, $e_{T a n}$, which are incoming angle-dependent functions, are given as follows:

$$
\begin{aligned}
& e_{N o r}=0.998-1.66 \theta+2.11 \theta^{2}-0.67 \theta^{3} \\
& e_{\text {Tan }}=0.993-1.76 \theta+1.56 \theta^{2}-0.49 \theta^{3} .
\end{aligned}
$$

In the above equations, $\theta$ is particle incidence angle (radians).

\subsection{Erosion modeling}

A typical erosion model has important terms: particle and wall properties, particle impact angle, and velocity. Most of erosion prediction models were developed empirically, and their basis was experimental data. In the following, to achieve more realistic results, three models developed by different authors are presented.

\subsubsection{Zhang model}

Zhang et al. [20] developed a model in Erosion/Corrosion Research Center of Tulsa University, USA. This model is presented in the following:

$$
\begin{aligned}
& E R=C(B H)^{-0.59} F_{s} V_{p}^{n} F(\theta), \\
& F(\theta)=5.4 \theta-10.11 \theta^{2}+10.93 \theta^{3}-6.33 \theta^{4}+1.42 \theta^{5},
\end{aligned}
$$

where $C$ is a constant value equal to $2.17 \times 10^{-7} ; B H$ is Brinell hardness; $V_{p}$ is particle-wall collision velocity; $F_{s}$ is particle shape factor, which is 1 for sharp edge (angular) particles, 0.53 for semi-rounded particles, and 0.2 for fully rounded particles; $\theta$ is the particlewall impact angle; and coefficient $n$ equals 2.41 .

\subsection{2. $D N V$ model}

The model was introduced in 2007 in the following way [35]:

$$
\begin{aligned}
& E R=K V_{p}^{n} F(\theta), \\
& F(\theta)=\sum_{i=1}^{i=8} A_{i}(\theta)^{i},
\end{aligned}
$$

where $K=2 \times 10^{-9}$ and $n=2.6$. The other coefficients may be calculated according to Table 1 . 
Table 1. Coefficients corresponding to DNV model.

\begin{tabular}{cccccccc}
\hline $\mathbf{A 1}$ & $\mathbf{A 2}$ & $\mathbf{A 3}$ & $\mathbf{A 4}$ & $\mathbf{A 5}$ & $\mathbf{A 6}$ & $\mathbf{A 7}$ & $\mathbf{A 8}$ \\
\hline 9.370 & -42.295 & 110.864 & -175.804 & 170.137 & -98.398 & 31.211 & -4.170 \\
\hline
\end{tabular}

\subsubsection{Oka model}

According to this model [21], the erosion rate at the arbitrary collision angle may be maintained by the erosion rate at $90^{\circ}$ angle and $g(\theta)$ function as follows:

$$
\begin{aligned}
& \operatorname{ER}(\theta)=10^{-9} \rho_{\mathrm{wall}} \mathrm{g}(\theta) \mathrm{E}_{90}, \\
& g(\theta)=(\sin \theta)^{n_{1}}(1+H \nu(1-\sin \theta))^{n_{2}}, \\
& E_{90}=K(H \nu)^{k_{1}}\left(\frac{V_{P}}{V^{*}}\right)^{k_{2}}\left(\frac{D_{P}}{D^{*}}\right)^{k_{3}},
\end{aligned}
$$

where $D^{*}(326 \mu)$ and $V^{*}(104 \mathrm{~m} / \mathrm{s})$ are related to reference values, $H v$ is Vickers hardness by GPa, and $n_{1}, n_{2}$, and $k_{2}$ are the coefficients calculated by:

$$
\begin{aligned}
& n_{1}=s_{1}(H \nu)^{q_{1}}, \\
& n_{2}=s_{2}(H \nu)^{q_{2}}, \\
& k_{2}=2.3(H \nu)^{0.038} .
\end{aligned}
$$

In addition, $K, k_{1}, k_{3}, s_{1}, s_{2}, q_{1}$, and $q_{2}$ are constant values that could be determined based on experimental data and according to particle and wall materials, available for different particles in [21]. In Eq. (24), $g(\theta)$ consists of two terms; the first term is related to plastic deformation and increases as the collision angle increases, while the second term presents the produced cutting and is maximum at zero angle. Both repeated deformation and cutting wear action are shown in Figure 2 .

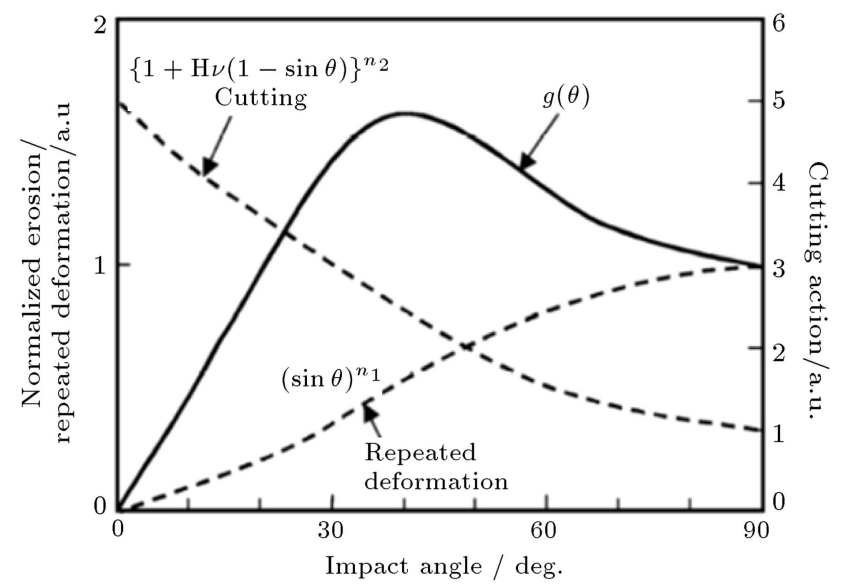

Figure 2. Repeated deformation and cutting wear action with impact angle [21].
Table 2. Flow conditions and material properties.

\begin{tabular}{lc}
\hline Carrier fluid & Air \\
\hline Fluid density & $1.225 \mathrm{~kg} / \mathrm{m}^{3}$ \\
Fluid viscosity & $1.795 \mathrm{e}-5 \mathrm{~kg} / \mathrm{m} . \mathrm{s}$ \\
Fluid velocity & $20 \mathrm{~m} / \mathrm{s}$ \\
Particle density & $2650 \mathrm{~kg} / \mathrm{m}^{3}$ \\
Particle diameter & $150,300 \mu \mathrm{m}$ \\
Particle mass flow rate & $1,3,5,10,15,20 \mathrm{~kg} /$ day \\
Pipe material & Steel 316 \\
Pipe density & $7990 \mathrm{~kg} / \mathrm{m}^{3}$ \\
\hline
\end{tabular}

\section{Geometries and boundary conditions}

In this study, erosion rates of four bend configurations, including sharp bend, standard elbow, $180^{\circ}$ pipe bend, and long elbow, are shown schematically in Figure 3 and are simulated. The diameters of all the pipes are $76.2 \mathrm{~mm}$, and the diameter upstream and downstream of the bend are extended 40 times. Figure 3 shows dimensions and sizes of the studied geometries. Boundary condition at the pipe inlet is velocity inlet, and that at the outlet is pressure outlet; the no-slip condition is applied at the wall. The flow conditions and material properties of pipe and particles are listed in Table 2.

\section{Mesh independency}

The entire grids inside of the pipes are structured hexahedrally. To perform the butterfly grid, the pipe cross-section is divided into five blocks, as shown in Figure 4(a), and structured quadrilateral grid is applied to the blocks; then, the grid is extended to the entire pipe. In this Figure, N1 and N2 are the numbers of grids on the lines on the cross-section. The distance of the first node to the surface is $0.025 \mathrm{~mm}$, which leads to a mean value of $y+$ of 1 on the first node away from the wall. To study mesh independency, four different meshes for standard elbow as listed in Table 3 are used in the simulations. According to Figure 5, the mesh with 2,640 grids on the cross-section is suitable for simulations. The final cross-section mesh and butterfly grid in 3D pipes used in all cases are depicted in Figures 4(b) and 6.

\section{Model validation}

In order to validate the numerical simulation results, the experimental data of Enayet et al. [36] are used. They measured the velocity profile and turbulence 

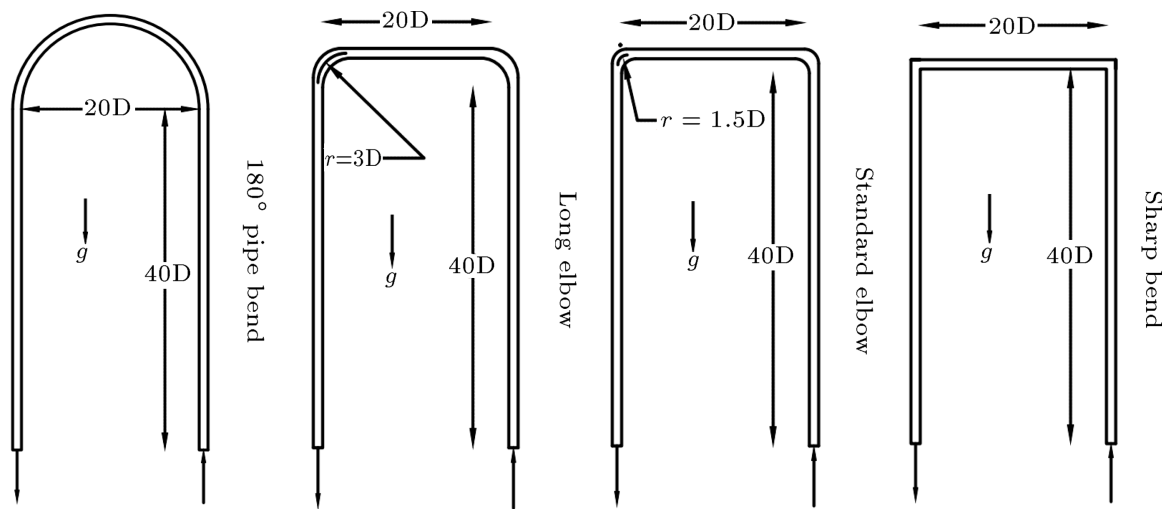

Figure 3. Schematic of the studied geometries.

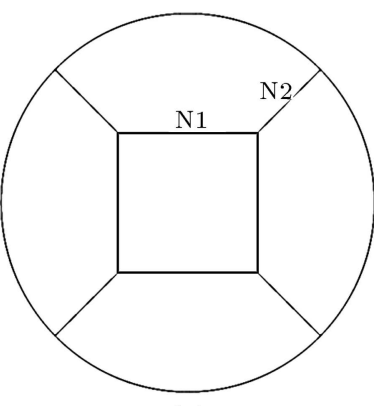

(a)

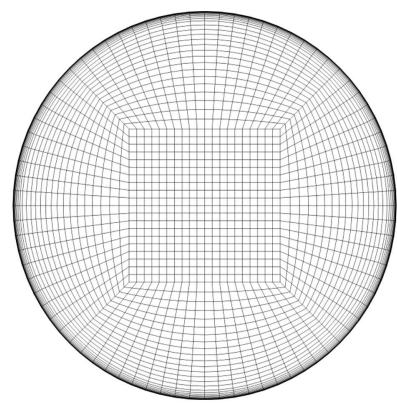

(b)

Figure 4. Cross-sectional view of the all geometries.

Table 3. Detail of grids to study mesh independency.

\begin{tabular}{cccc}
\hline Mesh\# & $(\mathbf{N 1}, \mathbf{N 2 )}$ & $\begin{array}{c}\text { Number of } \\
\text { grids on } \\
\text { cross-section }\end{array}$ & $\begin{array}{c}\text { Total } \\
\text { number } \\
\text { of grids }\end{array}$ \\
\hline 1 & $(15,15)$ & 1,125 & 562,500 \\
2 & $(15,20)$ & 1,425 & $1,140,000$ \\
3 & $(20,28)$ & 2,640 & $1,689,600$ \\
4 & $(25,35)$ & 4,125 & $2,227,500$ \\
\hline
\end{tabular}

intensity on several planes perpendicular to the flow direction in a $48 \mathrm{~mm}$ elbow with curvature radius of $134 \mathrm{~mm}$ using laser Doppler anemometry. Reynolds number of the flow is 43,000 based on the pipe diameter and the fluid viscosity of $0.001027 \mathrm{~kg} / \mathrm{ms}$ for water. For the CFD simulation of this case, a mesh is applied according to mesh 3 in Table 3 . The predicted velocity profiles and turbulence intensities on two planes, one at $\beta=30^{\circ}$ in the bend section and the other at a distance of on pipe diameter after the bend, are shown in Figures 7 and 8 and are compared with the experimental data of [36]. These figures show that the numerical simulation results are in satisfactory agreement with the experimental data for the mean velocity profiles and turbulence intensities.

To validate the erosion models, the experimental data of Zahedi et al. [26] are used. They measured the pipe wall thickness decrease and, consequently, the

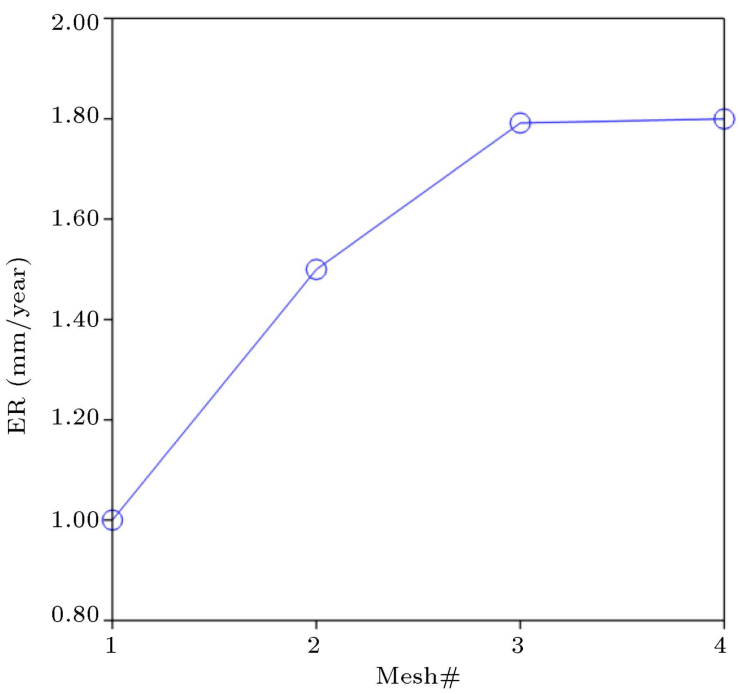

Figure 5. Maximum predicted erosion caused by $300 \mu \mathrm{m}$ particles with different grids.

maximum erosion in a 3 -inche elbow using Ultrasonic Technology with 11 to $27 \mathrm{~m} / \mathrm{s}$ air velocities for sharp edged $300 \mu \mathrm{m}$ particles. As may be seen in Figure 9, the Oka model showed higher accuracy than Zhang and DNV models did. The maximum relative error was less than $7 \%$ for Oka model and $9 \%$ for Zhang model; however, DNV model showed up to $50 \%$ error and predicted less value compared to experimental data. According to this, the Oka model is highly accurate and fit for use in future simulations.

\section{Results and discussion}

In order to simulate the erosion rate at the different bends, sharp edge (angular) particles with different sizes and mass flow rates are injected into the pipe. In all simulations, a total of 52,800 particles are tracked. For this number of particles, it was found that the maximum erosion rate remained unchanged with further increase of the number of tracked particles.

The erosion rate depends on the velocity of particle during collision with the wall. In carrier 

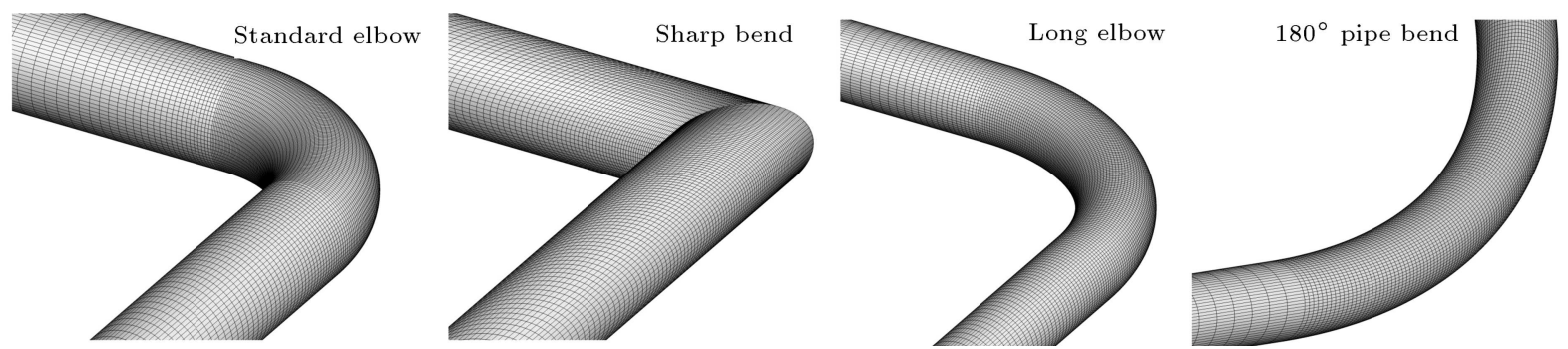

Figure 6. Isometric view of the selected grids.

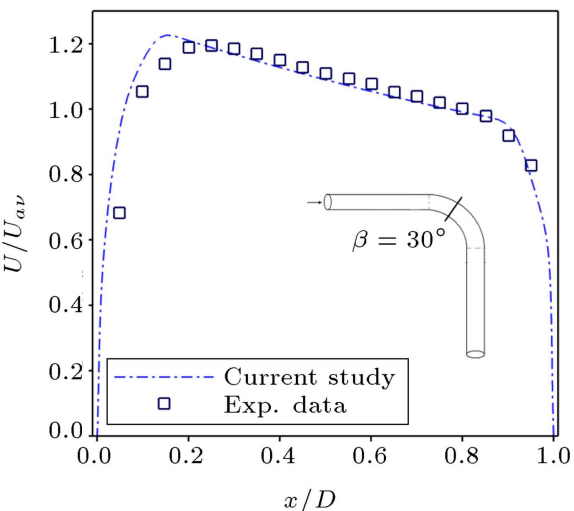

(a)

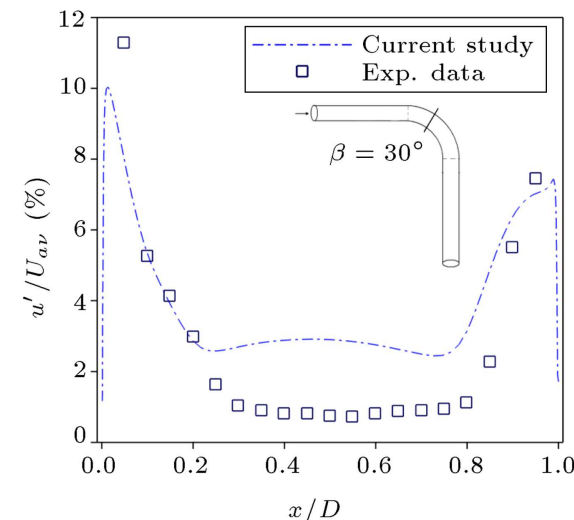

(b)

Figure 7. Comparison of the predicted velocity profile (a) and turbulence intensity (b) with the experimental data of [37] at $\beta=30^{\circ}$ in the bend section.

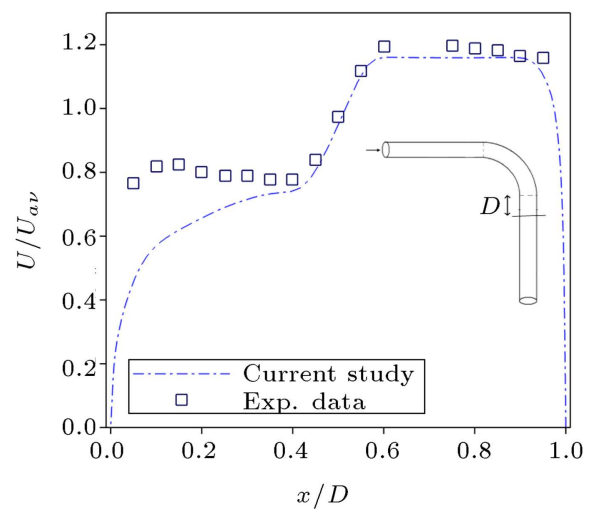

(a)

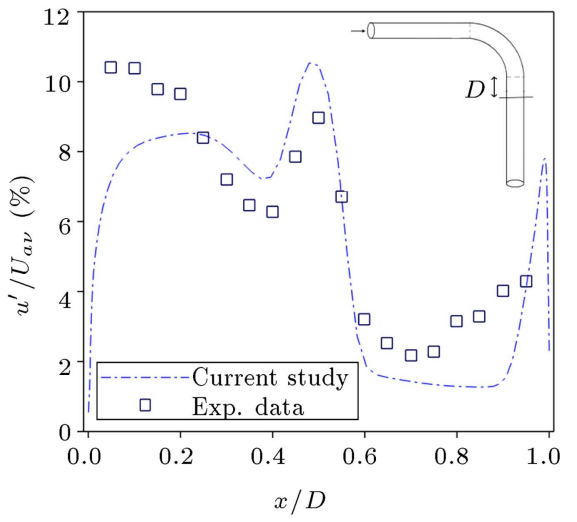

(b)

Figure 8. Comparison of the predicted velocity profile (a) and turbulence intensity (b) with the experimental data of [37] at $1 \mathrm{D}$ after the bend.

fluid flows with low viscosity and density, particle Stokes number is usually greater than 1 , and the sand particles do not follow the streamlines and gain direct forward motions, which in turn lead to severe collisions with the walls and, subsequently, a high level of erosion. The maximum erosion rate for different particle mass flow rates is shown in Figure 10 for the sharp elbow. On average, the erosion rate caused by $300 \mu \mathrm{m}$ particles at the first bend is by $20 \%$ higher than that of $150 \mu \mathrm{m}$ particle at the same particle flow rates. At the second bend, the erosion rate caused by $300 \mu \mathrm{m}$ particles is lower than that of $150 \mu \mathrm{m}$ ones by $28 \%$. This can be attributed to the fact that particle velocity is an important parameter affecting the erosion rate; given their normal collision with the surface of the first bend, the particles first lose their velocity component along the streamlines. Therefore, within the distance between the two bends, the $150 \mu \mathrm{m}$ particles accelerate to a higher velocity due to their smaller mass and cause a greater erosion rate at the second bend compared to $300 \mu \mathrm{m}$ particles. Mean particle velocity contours in several sections between the two bends are depicted in Figure 11. It is seen that the $150 \mu \mathrm{m}$ particles at the distance between the 


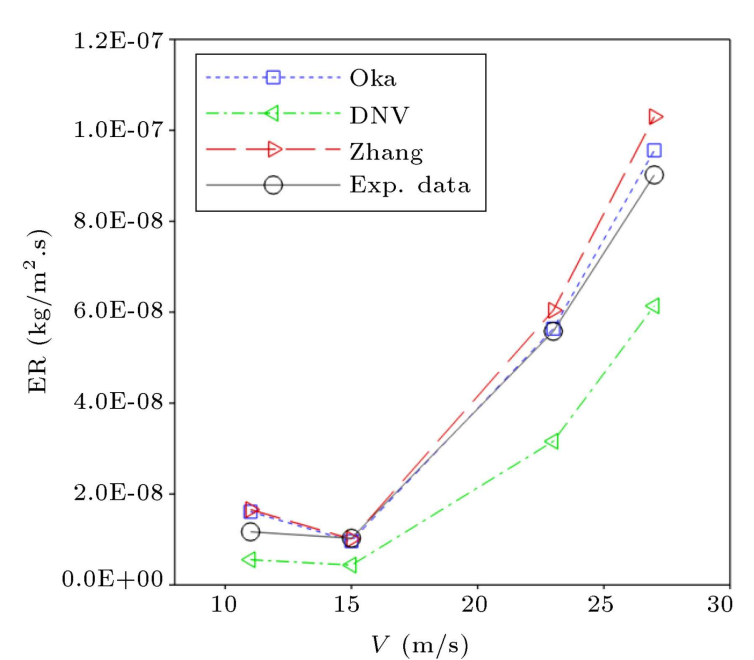

Figure 9. Comparison of the predicted maximum erosion rate with the experimental data of [26].

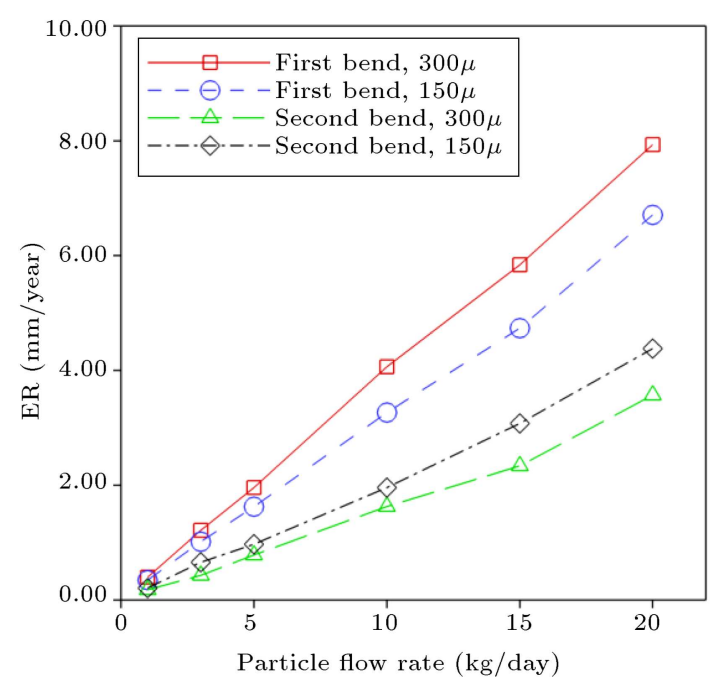

Figure 10. Maximum erosion rate at the sharp bend.

two bends accelerate to a higher velocity than 300 $\mu \mathrm{m}$ particles and have a higher particle-wall impact velocity at the second bend. Accordingly, the effect of particles' diameter on the erosion rate is not much as compared to particle velocity in this geometry. In addition, Figure 10 shows that the erosion rates caused by 300 and $150 \mu \mathrm{m}$ particles at the second bend are lower by $59 \%$ and $37 \%$, respectively, as compared to the first bend.

In Figure 12, the contours of erosion rate are shown for the particles of $300 \mu \mathrm{m}$ and flow rate of $10 \mathrm{~kg} /$ day at the first and second bends. In this case, the maximum erosion occurs at the first bend and along the line on the outer wall, as shown in Figure 13. The profile of the erosion rate along this line is depicted in Figure 13. This figure shows that the peak in the erosion rate is located on the outer wall and in the direction of the pipe center.

For the standard elbow, the maximum erosion

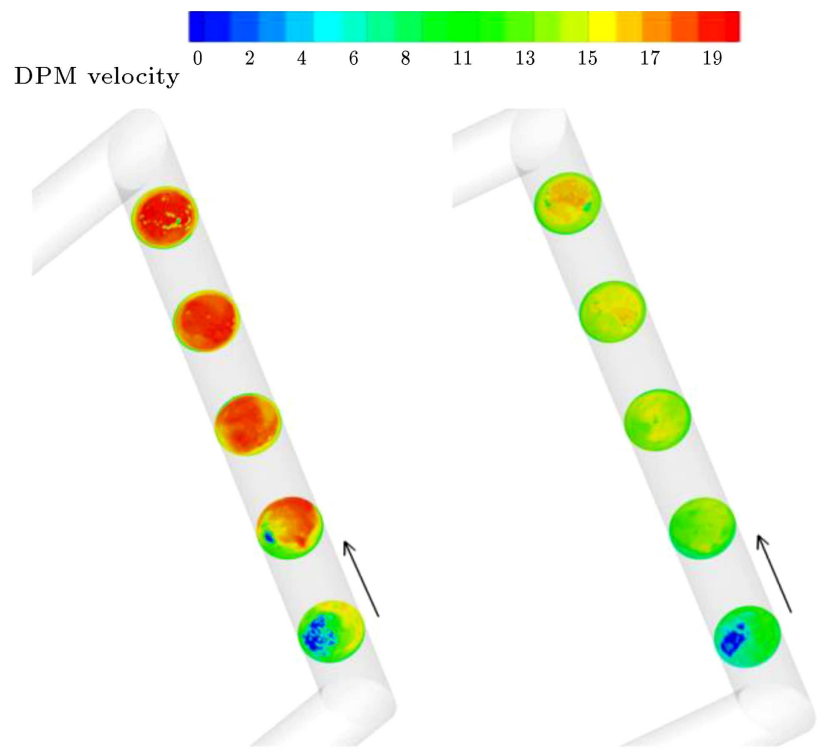

Figure 11. Mean particle velocity contours of $150 \mu \mathrm{m}$ (left) and $300 \mu \mathrm{m}$ particles (right) in several sections between the two bends.

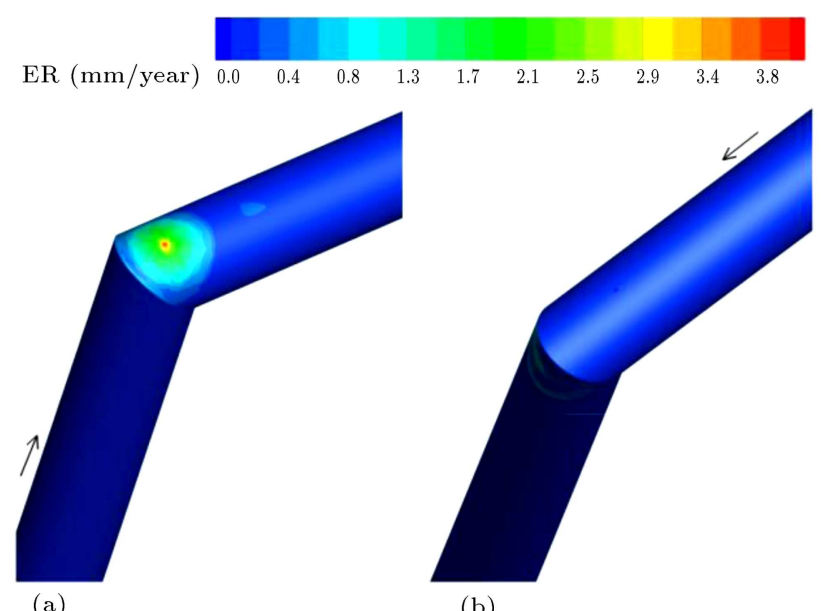

Figure 12. Contour of erosion rate caused by $300 \mu \mathrm{m}$ particles at the first (a) and second (b) bends for the sharp bend.

rate caused by $150 \mu \mathrm{m}$ particles is roughly the same at the first and second bends. For $300 \mu \mathrm{m}$ particles, however, the erosion rate at the second bend is $40 \%$ lower than that at the first bend. The erosion rate contours for $300 \mu \mathrm{m}$ particles for the first and second bends are shown in Figure 14. The maximum erosion at the first and second bends occurs at angles of $42^{\circ}$ and $58^{\circ}$, respectively. The erosion pattern at the first bend is similar to numerical predictions presented by other researchers [27] for the single standard elbow.

The contour of the erosion rate caused by 300 $\mu \mathrm{m}$ particles in the long elbow is shown in Figure 15. Under the same conditions, the maximum erosion rates caused by both 150 and $300 \mu \mathrm{m}$ particles are on average 


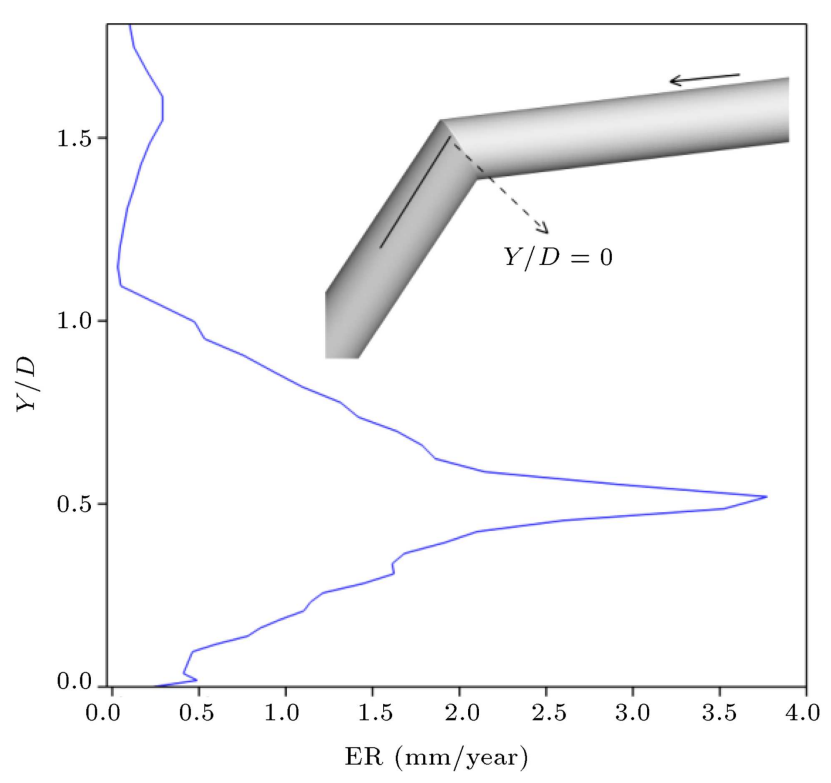

Figure 13. Profile of erosion rate along the line on the outer wall at the first bend.

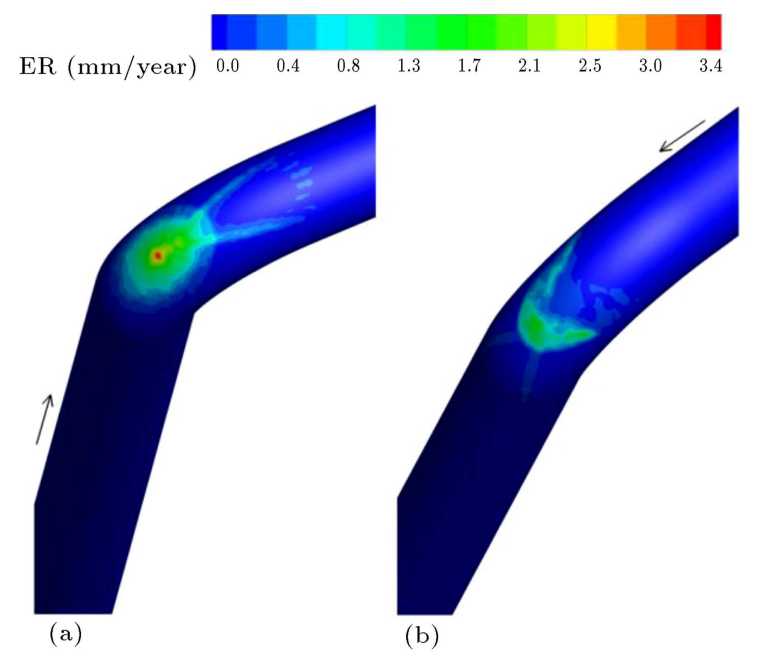

Figure 14. Contour of erosion rate caused by $300 \mu \mathrm{m}$ particles at the first (a) and second (b) bends for the standard elbow.

$26 \%$ lower than that of the standard elbow at the first bend. Regarding the second bend, employing the long elbow decreases the erosion rates caused by 300 and $150 \mu \mathrm{m}$ particles by $12 \%$ and $37 \%$, respectively. Moreover, the maximum erosion rates at the first and second bends occurs at angles of $32^{\circ}$ and $53^{\circ}$, respectively. The erosion pattern at the second bend is similar to that at the first bend, yet with lower intensity. This is consistent with Figure 16, where the maximum erosion rate at different particle mass flow rates for the second bend is lower than that for the first bend.

Wang and Shirazi [37] developed an equation for the ratio of the erosion rate of long elbow $\left(E R_{r / D}\right)$ and standard elbows $\left(E R_{\text {std }}\right)$. Accordingly:

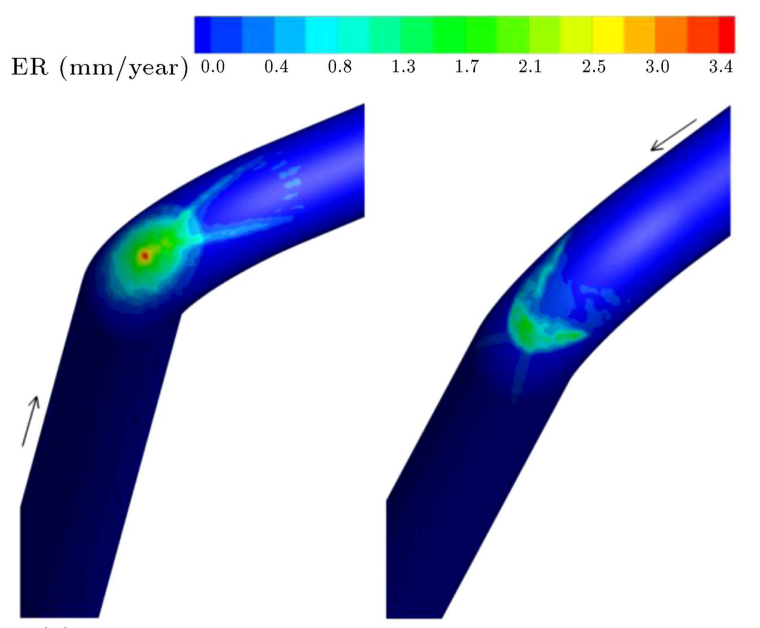

(a)

(b)

Figure 15. Contour of erosion rate caused by $300 \mu \mathrm{m}$ particles at the first (a) and second (b) bends for the long elbow.

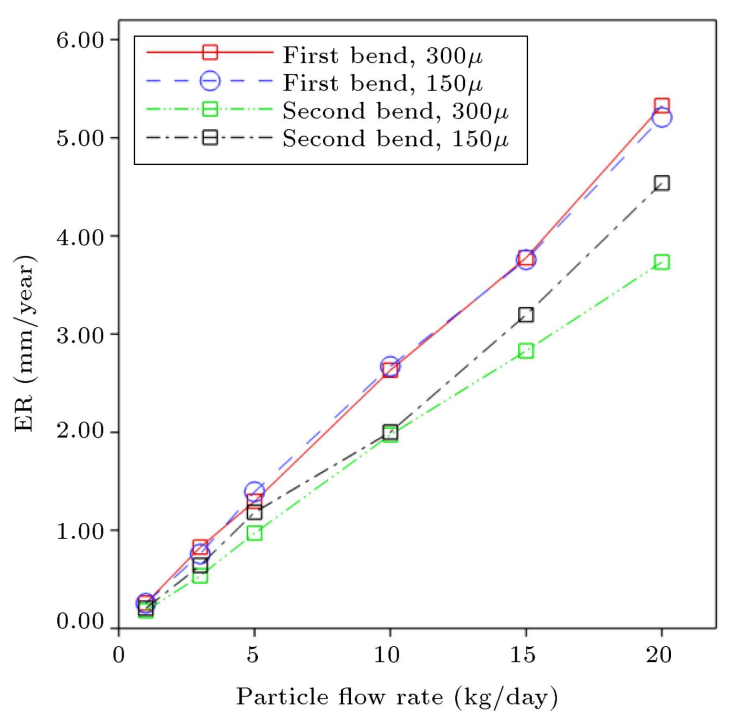

Figure 16. Maximum erosion rate in the long elbow.

$$
\begin{aligned}
\frac{E R_{r / D}}{E R_{\text {std }}}= & \exp \left(-\left(\left(0.1 \rho_{f}^{0.4} \mu_{f}^{0.65}\right) / d^{0.3}+0.015 \rho_{f}^{0.25}\right.\right. \\
& +0.12) \times(r / D-1.5))
\end{aligned}
$$

where $\rho_{f}, \mu_{f}$, and $d$ are the fluid density, the fluid viscosity, and particle diameter, respectively. Based on this equation, the erosion rate caused by 150 and $300 \mu \mathrm{m}$ particles carried by air in long elbows $(r / D=$ 3 ) is $20 \%$ lower than that of standard elbow, which is in good agreement with the results of this study.

For the $180^{\circ}$ pipe bend, the profile of the erosion rate caused by $300 \mu \mathrm{m}$ particles at different angles is shown in Figure 17. In addition, it is shown that the maximum erosion occurs at $18^{\circ}$ from the inlet of the bend. Using the $180^{\circ}$ pipe bend leads 


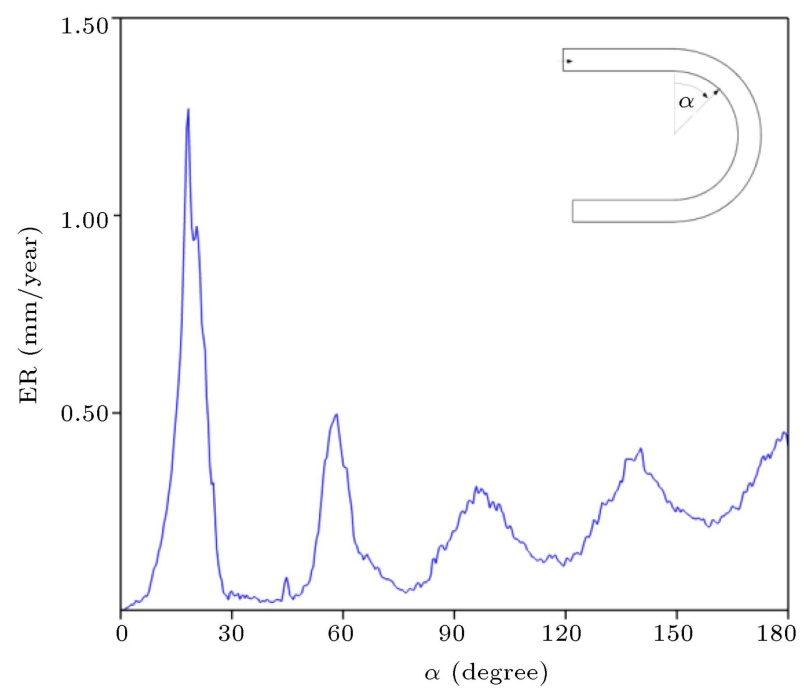

Figure 17. Erosion distribution as a function of $\alpha$ for $180^{\circ}$ pipe bend.

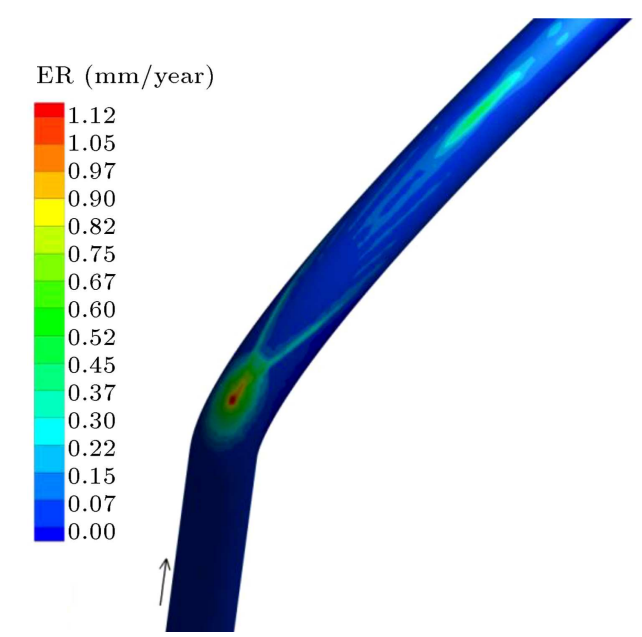

Figure 18. Contour of erosion rate caused by $300 \mu \mathrm{m}$ particles at the $180^{\circ}$ pipe bend.

to the lowest erosion rate as compared to the sharp bend and standard and long elbows. Under the same conditions, the erosion is decreased by $67 \%, 64 \%$, and $52 \%$ for sharp bend and standard and long elbows, respectively, when the $180^{\circ}$ pipe bend is used. The contour of the erosion rate caused by $300 \mu \mathrm{m}$ particles in the $180^{\circ}$ pipe is shown in Figure 18 . For this configuration, the location of maximum erosion is similar for $150 \mu \mathrm{m}$ sand size. It can be seen that the erosion is distributed more uniformly through the bend. Due to the increased curvature of return bend and a consequent decreased disturbance in the flow field, the erosion rate is significantly reduced. The maximum erosion rate at different mass flow rates is shown in Figure 19. According to this figure, the effect of particles' diameter on the erosion rate is not much in this geometry.

Under the same conditions, employing $180^{\circ}$ pipe

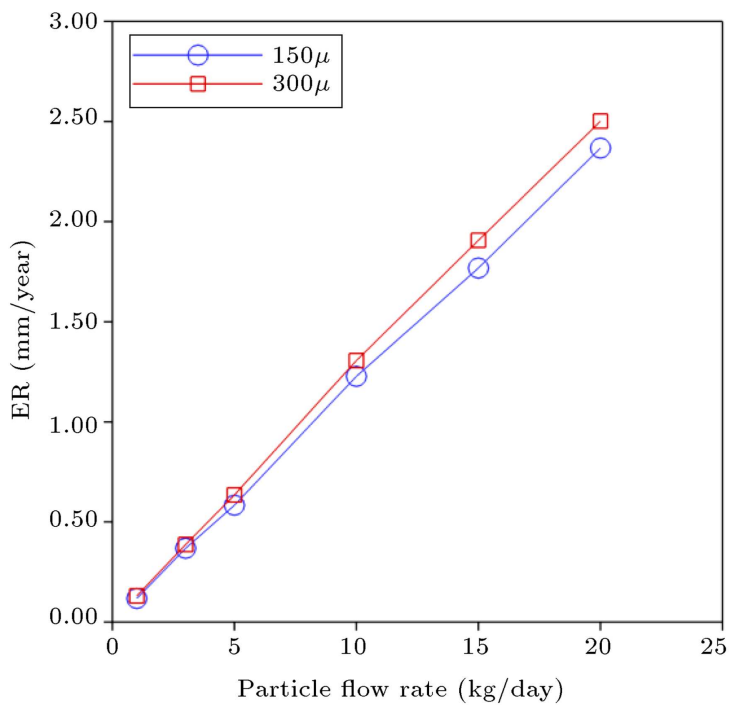

Figure 19. Maximum erosion rate at the $180^{\circ}$ pipe bend with respect to the particle mass flow rate.

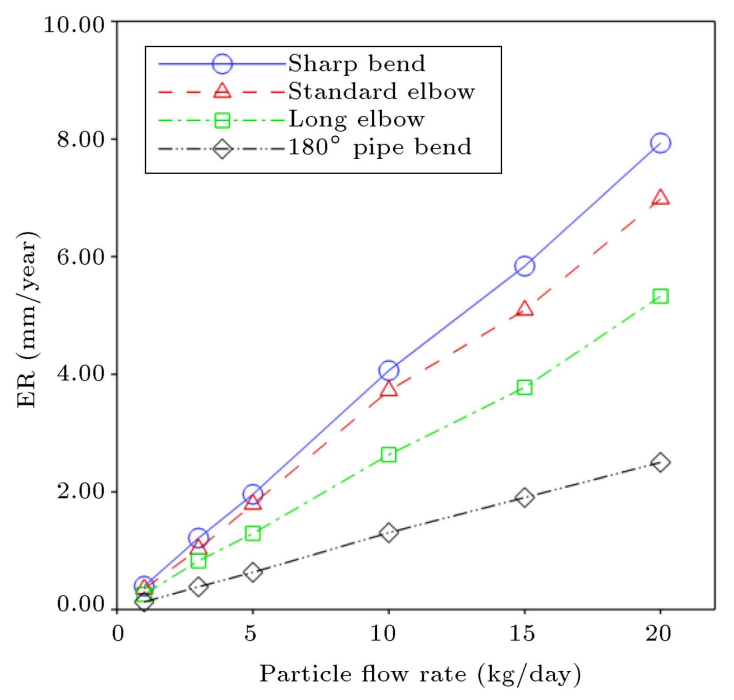

Figure 20. Comparison between the maximum erosion rates caused by $300 \mu \mathrm{m}$ particles for all cases studied.

bend at return bends results in the lowest level of erosion, while the maximum erosion occurs in sharp bends, as shown in Figure 20. The maximum erosion rate is linearly proportional to the particle mass flow rate for all cases. Mainly, as the particle mass flow rate increases, the collision number between wall and particles increases, resulting in a higher erosion rate. It is also found that the $180^{\circ}$ pipe bend is less sensitive to the increase of particle mass flow rate, and the slope of the maximum erosion profile caused by $300 \mu \mathrm{m}$ particles is about one third of the standard elbow.

\section{Conclusion}

In this study, the erosion rate resulting from gasparticle flows at return pipe bends was investigated. 
Initially, available experimental data were used to validate the CFD models for the elbow. Several models for evaluating the erosion rate, including those of Zhang, DNV, and Oka, were used in a standard elbow; the results of these models were compared with the experimental data in related literature. It was shown that the Oka model produced more realistic results than other models did. Afterwards, a comprehensive CFD-based erosion simulation was performed using the Oka model for several vertical return bends including sharp bend, standard elbow, long elbow, and $180^{\circ}$ pipe bend. Particle sizes of 150 and $300 \mu \mathrm{m}$ were considered. The results indicated that, in the studied geometries, the erosion rate linearly increased by increasing the particle mass flow rate. In addition, it was found that the $180^{\circ}$ pipe bend at return bends had better erosion performance than other geometries did and experienced lower erosion rates by 67, 64, and 52 percent as compared to the sharp bend, standard, and long elbows, respectively. For the configurations with two bends mounted in series, the erosion pattern was similar to that at the single bend; however, the maximum erosion at the second bend was lower than that at the first bend.

\section{References}

1. True, M.E. and Weiner, P.D. "A laboratory evaluation of sand erosion of oil gas well producing equipment", In Annual Meeting Papers, Division of Production, American Petroleum Institute (1976).

2. Mansouri, A. "A combined CFD-experimental method for developing an erosion equation for both gas-sand and liquid-sand flows", E/CRC, The University of Tulsa (2016).

3. Shirazi, S.A., McLaury, B.S., Sow, E., Butter, M.K., Folefac, A.N., and Hassaballa, S. "Sand settling and locations of high erosion in subsea production system", In Trinidad and Tobago Energy Resources Conference, Society of Petroleum Engineers (2010).

4. Finnie, I. "Erosion of surfaces by solid particles", Wear, 3(2), pp. 87-103 (1960).

5. Bitter, J.G.A. "A study of erosion phenomena, Part I", Wear, 6(1), pp. 5-21 (1963).

6. Sheldon, G.L. and Finnie, I. "On the ductile behavior of nominally brittle materials during erosive cutting", Journal of Engineering for Industry, 88(4), pp. 387392 (1966).

7. American Petroleum Institute. Production Dept. "API recommended practice for design and installation of offshore production platform piping systems", American Petroleum Institute (1981).

8. Salama, M.M. and Venkatesh, E.S. "Evaluation of API RP 14E erosional velocity limitations for offshore gas wells", In Offshore Technology Conference (1983).
9. Russell, R., Shirazi, S., and Macrae, J. "A new computational fluid dynamics model to predict flow profiles and erosion rates in downhole completion equipment", In SPE Annual Technical Conference and Exhibition, Society of Petroleum Engineers (2004).

10. Shirazi, S.A. "Threshold Velocities How fast can you flow and still avoid sand erosion problem", E/CRC, The University of Tulsa (1994).

11. Chen, X., McLaury, B.S., and Shirazi, S.A. "Effects of applying a stochastic rebound model in erosion prediction of elbow and plugged tee", In ASME 2002 Joint US-European Fluids Engineering Division Conference, pp. $247-254$ (2002).

12. Grant, G. and Tabakoff, W. "Erosion prediction in turbomachinery resulting from environmental solid particles", Journal of Aircraft, 12(5), pp. 471-478 (1975).

13. Oka, Y.I., Okamura, K., and Yoshida, T. "Practical estimation of erosion damage caused by solid particle impact: Part 1: Effects of impact parameters on a predictive equation", Wear, 259(1-6), pp. 95-101 (2005).

14. Abdulla, A. "Estimating erosion in oil and gas pipe line due to sand presence", Master Thesis, Blekinge Institute of Technology, Karlskrona, Sweden (2011).

15. Mazumder, Q.H. "Effect of liquid and gas velocities on magnitude and location of maximum erosion in Ubend", Open Journal of Fluid Dynamics, 2(2), p. 29 (2012).

16. Mazumder, Q.H. "S-bend erosion in particulated multiphase flow with air and sand", The Journal of Computational Multiphase Flows, 8(3), pp. 157-166 (2016).

17. Pereira, G.C., de Souza, F.J., and de Moro Martins, D.A. "Numerical prediction of the erosion due to particles in elbows", Powder Technology, 261, pp. 105117 (2014).

18. Ahlert, K.R. "Effects of particle impingement angle and surface wetting on solid particle erosion of AISI 1018 steel", Doctoral Dissertation, University of Tulsa (1994).

19. Neilson, J.H. and Gilchrist, A. "Erosion by a stream of solid particles", Wear, 11(2), pp. 111-122 (1968).

20. Zhang, Y., Reuterfors, E.P., McLaury, B.S., Shirazi, S.A., and Rybicki, E.F. "Comparison of computed and measured particle velocities and erosion in water and air flows", Wear, 263(1-6), pp. 330-338 (2007).

21. Oka, Y.I., Ohnogi, H., Hosokawa, T., and Matsumura, M. "The impact angle dependence of erosion damage caused by solid particle impact", Wear, 203, pp. 573579 (1997).

22. Fan, J.R., Luo, K., Zhang, X.Y., and Cen, K.C. "Large eddy simulation of the anti-erosion characteristics of the ribbed-bend in gas-solid flows", Journal of Engineering for Gas Turbines and Power, 126(3), pp. 672679 (2004). 
23. Chen, J., Wang, Y., Li, X., He, R., Han, S., and Chen, Y. "Erosion prediction of liquid-particle two-phase flow in pipeline elbows via CFD-DEM coupling method", Powder Technology, 275, pp. 182-187 (2015).

24. Mansouri, A., Arabnejad, H., Karimi, S., Shirazi, S.A., and McLaury, B.S. "Improved CFD modeling and validation of erosion damage due to fine sand particles", Wear, 338, pp. 339-350 (2015).

25. Vieira, R.E., Mansouri, A., McLaury, B.S., and Shirazi, S.A. "Experimental and computational study of erosion in elbows due to sand particles in air flow", Powder Technology, 288, pp. 339-353 (2016).

26. Zahedi, P., Karimi, S., Mahdavi, M., McLaury, B.S., and Shirazi, S.A. "Parametric analysis of erosion in 90 degree and long radius bends", In ASME 2016 Fluids Engineering Division Summer Meeting Collocated with the ASME 2016 Heat Transfer Summer Conference and the ASME 201614 th International Conference on Nanochannels, Microchannels, and Minichannels, American Society of Mechanical Engineers (2016).

27. Duarte, C.A.R., de Souza, F.J., and dos Santos, V.F. "Mitigating elbow erosion with a vortex chamber", Powder Technology, 288, pp. 6-25 (2016).

28. Zheng, C., Liu, Y., Wang, H., Zhu, H., Liu, Z., Cai, B., and Shen, Y. "Numerical study on improving the erosion life of ball seat for oil and gas reservoir fracturing", Engineering Failure Analysis, 60, pp. 188198 (2016).

29. Zehtabiyan-Rezaie, N., Zarandi, F., Hossein, M., and Saffar-Avval, M. "Generalized heat transfer and entropy generation of stratified air-water flow in entrance of a mini-channel", Scientia Iranica, 24(5), pp. 24072417 (2017).

30. Banakermani, M.R., Naderan, H., and Saffar-Avval, M. "An investigation of erosion prediction for $15^{\circ}$ to $90^{\circ}$ elbows by numerical simulation of gas-solid flow", Powder Technology, 334, pp. 9-26 (2018).

31. Fluent AN. 18.2, Theory Guide, ANSYS Inc. Canonsburg, PA (2017).

32. Sajjadi, H., Salmanzadeh, M., Ahmadi, G., and Jafari, S. "Investigation of particle deposition and dispersion using Hybrid LES/RANS model based on lattice Boltzmann method", Scientia Iranica, 25(6) (2018). DOI: $10.24200 /$ sci. 2018.20723

33. Parsi, M., Agrawal, M., Srinivasan, V., Vieira, R.E., Torres, C.F., McLaury, B.S., and Shirazi, S.A. "CFD simulation of sand particle erosion in gas-dominant multiphase flow", Journal of Natural Gas Science and Engineering, 27, pp. 706-718 (2015).

34. Haider, A. and Levenspiel, O. "Drag coefficient and terminal velocity of spherical and nonspherical particles", Powder Technology, 58(1), pp. 63-70 (1989).

35. Veritas, D.N. "Recommended Practice RP O501 erosive wear in piping systems", DNV Recommended Practice, 4 (2007).
36. Enayet, M.M., Gibson, M.M., Taylor, A.M.K.P., and Yianneskis, M. "Laser-Doppler measurements of laminar and turbulent flow in a pipe bend", International Journal of Heat and Fluid Flow, 3(4), pp. 213-219 (1982).

37. Wang, J. and Shirazi, S.A. "A CFD based correlation for erosion factor for long-radius elbows and bends", Journal of Energy Resources Technology, 125(1), pp. 26-34 (2003).

\section{Biographies}

Ali Farokhipour received his BS degree in Aerospace Engineering from K. N. Toosi University of Technology, Iran in 2011 and an MS degree in Mechanical Engineering from Amirkabir University of Technology (Tehran Polytechnic), Iran in 2013, where he is currently a $\mathrm{PhD}$ degree student. His research interests include computational fluid dynamics, gas turbine, non-premixed combustion, solid particle erosion, and multiphase flows.

Zohreh Mansoori is an Associate Professor of Mechanical Engineering and the Head of Energy Research Center at Amirkabir University of Technology (AUT), Tehran, Iran. She received her BSc degree from Amirkabir University of Technology in 1990, an MS degree in Mechanical Engineering from K. N. Toosi University of Technology, Iran in 1994, and her PhD degree from AUT in 2002. Her research contributions are in the fields of computational fluid dynamics, multiphase flows, particle transport, heat transfer, thermal systems, and energy management.

Majid Saffar-Avval is a Professor of Mechanical Engineering at Amirkabir University of Technology (AUT), Tehran, Iran. He received his BSc and MSc degrees from Sharif University of Technology and his PhD degree from the Ecole Nationale Superieure des Arts et Metiers (ENSAM), Paris, France in 1985. He has been teaching at AUT since then. He was the Head of the Mechanical Engineering Department from June 2000 to June 2002 and the Head of the Energy and Control Center of Excellence from May 2007 to March 2012 at AUT. His research contributions are in the fields of two-phase heat transfer, advanced thermal systems, energy management, and bio-heat transfer.

Goodarz Ahmadi received his $\mathrm{PhD}$ degree in Mechanical Engineering from the Purdue University, West Lafayette, IN, USA and is now a Professor of Mechanical Engineering at Clarkson University, USA. His research work concerns include particle transport, deposition and removal, aerosol mechanics, stochastic processes in engineering, advance theory of turbulence, and multiphase flow modeling. 